Андрій Олександрович Зінченко (доктор техн. наук, доцент) ${ }^{1}$ Олександр Миколайович Нестеров ${ }^{1}$

Катерина Андріїва Зінченко ${ }^{2}$

\author{
${ }^{1}$ Національний університет оборони Украӥни імені Івана Черняховського, Киӥв, Украӥна \\ ${ }^{2}$ Військовий інститут телекомунікацій та інформатизаціӥ імені Героӥв Крут, Київ, Украйна
}

\title{
ДО ПИТАННЯ ПРОПУСКНОЇ СПРОМОЖНОСТІ ЯК ОСНОВНОГО ПОКАЗНИКА ЕФЕКТИВНОСТІ ФУНКЦІОНУВАННЯ СИСТЕМИ ВІЙСЬКОВОГО ЗВ'язКУ
}

У статті на основі проведеного аналізу встановлено невідповідність між існуючим науковометодичним апаратом оцінки ефективності функиіонування системи військового зв'язку, який орієнтований на аналогові методи передачі даних, та здійсненим переходом системи військового зв'язку на ицифрові засоби зв'язку. Обтрунтовано необхідність: удосконалення методу розрахунку пропускної спроможності мережі доступу до транспортної мережі системи зв'язку за умов переходу на сучасні циифрові методи передачі інформації, зростання інформаційного обміну, реалізації мультисервісних мереж надання послуг; розробки методу управління наявними ресурсами транспортної мережі системи військового зв'язку для гарантованого забезпечення необхідної пропускної спроможності системи зв'язку в складних умовах ведення бойових дій. В подальшому удосконалені методи можуть бути використані для обтрунтування вимог до системи військового зв'язку у бойових діях (операціях).

Ключові слова: система зв'язку, система управління, інформаційний напрямок, інформаційна система, канал зв'язку, пропускна спроможність, автоматизована система управління.

\section{Вступ}

Управління військами в сучасних умовах ведення операцій (бойових дій) $є$ складним процесом, основний зміст якого складають: безперервний збір, вивчення та узагальнення даних обстановки; прийняття рішень; доведення наказів, розпоряджень та сигналів бойового управління до підлеглих військ; моделювання та планування бойових дій (операцій), видача службовим особам пунктів управління довідкової інформації; організація та підтримка взаємодії; організація та проведення заходів 3 підтримки боєготовності військ; організація всебічного забезпечення; постійний контроль за виконанням поставлених завдань та надання підлеглим необхідної допомоги.

Постановка проблеми. Виконання перелічених вище завдань неможливе без надійного та ефективного функціонування системи зв'язку. Основними показниками для оцінки ефективності функціонування системи зв'язку $\epsilon$ : бойова готовність, стійкість, мобільність, пропускна спроможність, розвідзахищеність.

Аналіз останніх досліджень і публікацій. Існуючий науково-методичний апарат визначення ефективності функціонування системи військового зв'язку за наведеними показниками застарів [1], розроблений ще за часів СРСР, орієнтований на застосування аналогових засобів зв'язку. Він не враховує нові способи бойового застосування та тактико-технічні характеристики сучасних цифрових засобів зв'язку, які надійшли на озброєння військ зв'язку ЗС України протягом 2014-2018 років [2]. Такий стан речей в подальшому може привести до зниження ефективності функціонування системи зв'язку в процесі управління військами (силами).

Мета статті. Проведення аналізу факторів, які впливають на ефективність функціонування системи військового зв'язку для розробки в подальшому науково-методичного апарату 3 можливістю використання єдиного показника для оцінки ефективності функціонування системи військового зв'язку.

\section{Виклад основного матеріалу дослідження.}

Система зв'язку на початку проведення антитерористичної операції була не спроможна забезпечити своєчасну передачу необхідного потоку інформації із необхідними вимогами до зв'язку щодо своєчасності, достовірності та скритності інформації, що передається. Таким чином виникла потреба у створені системи зв'язку, яка повинна вирішити питання обміну інформації iз заданими вимогами в інтересах управління військами, 3 можливістю у будь-який час та за будь-яких умов обстановки наростити спроможності системи зв'язку та забезпечити необхідні сервіси для користувачів в системі управління військами. Відповідно із [3], основними сервісами на сьогоднішній день $\epsilon$ : відкритий автоматичний телефонний зв'язок; автоматичний телефонний зв'язок в мережі обміну службовою інформацією (МОСI); автоматичний телефонний зв'язок в захищеній системі обробки 
інформації (3СОI); передача даних (ПД) в мережах АCУ "Дніпро", МОCI, ЗСОI; відео конференційний зв'язок в мережі ЗСОI; послуги в мережі ІСД-Інтернет. Такий підхід до функціонування системи зв'язку не враховує потребу у забезпечені надійного функціонування автоматизованих систем управління (АСУ) військами та інформаційних систем (IC) різного призначення. До таких IC в 3C України відносяться АСУ артилерією “Кропива”, “Віражпланшет”, “Ореанда”, інтеграційна платформа “Дельта", тощо [2]. Також існує потреба врахування під час визначення потрібних характеристик системи зв'язку ОТУВ сенсорних засобів, що будуть передавати інформацію у різному вигляді до центрів іiі обробки i узагальнення та користувачів. До сенсорних засобів можливо віднести засоби повітряної розвідки, засоби радіолокаційної та артилерійської розвідки, оптичні, тепловізійні комплекси та звукометричні комплекси.

За короткий термін інформаційнотелекомунікаційні вузли пунктів управління (ПУ) військових частин та оперативно-тактичних угруповань були забезпечені сучасними цифровими засобами зв'язку. Завдяки ним відбувся перехід системи зв'язку ЗС України від аналогових до цифрових засобів зв'язку. Впроваджено було наступні телекомунікаційні засоби [2]: станції супутникового зв'язку Тooway; комплекти засобів транкінгового зв'язку Motorola; сучасні цифрові радіорелейні станції Р-414МУ, Р425C3; модеми для проводового зв'язку М-2Е1Eth-2DSLbis, M-4DSL bis; точки доступу AirGrid та NanoBridge; станція широкосмугового зв'язку P-402; радіостанції виробництва корпорації HARRIS короткохвильового та ультракороткохвильового діапазону та інше телекомунікаційне обладнання. Проте більшість 3 них, це цивільні телекомунікаційні рішення, які не розраховані на експлуатацію в умовах ведення бойових дій [4-18].

В ситуації, що склалась, виникає необхідність побудувати транспортну (первину) мережу зв'язку, яка б поєднувала пункти управління між собою та інтегрувала розосереджені засоби розвідки різного призначення до єдиного інформаційного середовища. При цьому, для гарантованого забезпечення зв'язку в будь-яких умовах обстановки, у тому числі під впливом засобів РЕБ та вогневого ураження противника, транспортна мережа повинна будуватися за принципом комплексного застосування різних засобів зв'язку на інформаційних напрямках [2].

Прийняті рішення щодо організації зв'язку на основі сучасних цифрових засобів зв'язку лише частково забезпечили виконання вимог до системи військового зв'язку. Аналіз існуючої системи зв'язку, проведений в [4-10, 11, 13-18], показав наступні недоліки в функціонуванні: телекомунікаційна мережа загального користування (ТМЗК), яку використовують в якості опорної мережі зв'язку, не забезпечує оперативне та якісне вирішення завдань управління через зниження якості в часи пікових навантажень; за оренду ТМЗК витрачаються значні кошти; системи супутникового зв'язку цивільного призначення, чутливі до змін в погодних умовах, не працюють в русі, вартість трафіку потребує невиправданих витрат коштів; відсутнє резервування основних засобів зв'язку на пункті управління та каналів зв'язку на напрямку; цивільне радіорелейне обладнання демаскує ITВ та знижує їх мобільність під час розгортання та згортання, у зв'язку з тим, що таке обладнання розгортається на телевежах $\mathrm{i}$ тому потребує додаткових дозволів; відсутність системи хибних пунктів управління.

Основним функціональним призначенням системи військового зв'язку $\epsilon$ забезпечення своєчасної передачі (доставки) заданого потоку повідомлень, необхідного для управління військами. При організації системи військового зв'язку важливе місце буде займати розробка варіантів структури системи військового зв'язку у відповідності 3 вимогами, що висуваються до системи військового зв'язку: постійній бойовій готовності, пропускній спроможності, стійкості, мобільності, розвідзахищеності. Ключове місце серед цих показників займає пропускна спроможність. В свою чергу пропускна спроможність тісно пов'язана 3 іншими показниками. Тому при розробці варіантів організації системи зв'язку першочергове завдання буде полягати у забезпеченні необхідної пропускної спроможності напрямків зв'язку. Також необхідно враховувати потребу у постійному збільшенні вимог до пропускної спроможності через збільшення кількості інформації, що циркулює у системі управління.

Для успішного вирішення завдання організації системи військового зв'язку необхідно знати кількість інформаційних повідомлень, що необхідно передати на напрямках зв'язку, для кожного 3 видів сервісів, що забезпечуються на пунктах управління [3-5]. В сучасних умовах, активного впровадження цифрових технологій передачі інформації 3 інтеграцією всіх видів трафіка, мова йде про швидкість передачі даних від кінцевої апаратури з подальшим її об'єднанням у цифрові потоки. При цьому завдання визначення необхідної пропускної спроможності розділиться на дві складові - визначення пікового навантаження кінцевих користувачів за умови інтеграції всіх видів трафіку на напрямках зв'язку та пропускної спроможності мережі доступу i первинної (транспортної) мережі. При цьому повинні виконуватись вимоги

$$
\begin{gathered}
\lambda \leq \mathrm{C}_{\mathrm{MД}}, \\
\mathrm{C}_{\mathrm{M}} \leq \mathrm{C}_{\mathrm{TM}} .
\end{gathered}
$$

де $\lambda$ - сумарне пікове навантаження всіх користувачів на напрямку зв'язку; $\mathrm{C}_{\mathrm{Mд}}-$ пропускна спроможність мережі 
доступу;

$\mathrm{C}_{\mathrm{TM}}{ }^{-}$

пропускна

спроможність

транспортної мережі.

Відповідно [3-5] розрізняють теоретичну пропускну спроможність (шеннонівську), технічну та експлуатаційну пропускну спроможність.

Теоретична пропускна спроможність характеризує максимально досяжну швидкість передавання у каналі зв'язку. Визначається теоретичною досяжністю швидкості передавання (біт/с) та не залежить від апаратури, що використовується. Вона описується аналітичним виразом, що враховує відношення сигнал/шум у каналі зв'язку:

$$
\mathrm{C}=\mathrm{B} \log _{2}\left(1+\mathrm{SNR}_{\text {дб }}\right) .
$$

де $\mathrm{C}$ - пропускна спроможність каналу у бітах у секунду;

В - ширина полоси пропускання каналу у герцах.

$$
\mathrm{SNR}_{\text {дб }}=10 \log \frac{\mathrm{P}_{\mathrm{c}}}{\mathrm{P}_{\amalg}}-\text { перевищення рівня }
$$

сигналу над рівнем шуму у децибелах (відношення сигнал/шум);

$$
\begin{aligned}
& \mathrm{P}_{\mathrm{c}} \text { - потужність корисного сигналу; } \\
& \mathrm{P}_{\text {ш }} \text { - потужність шуму. }
\end{aligned}
$$

Фактично, це можлива швидкість передачі у вибраному фізичному середовищі та смузі частот. При цьому повинні виконуватись умови:

$$
\begin{aligned}
& \mathrm{C}_{\mathrm{M}} \leq \mathrm{C}, \\
& \mathrm{C}_{\mathrm{TM}} \leq \mathrm{C} .
\end{aligned}
$$

Технічна пропускна спроможність $\left(\mathrm{C}_{\mathrm{T}}\right)$ характеризує досягнуту швидкість передачі. Для транспортної мережі та мережі доступу вона визначається технічними можливостями кінцевої апаратури зв'язку. Фактично, в ідеальних умовах, мова йде про співвідношення:

$$
\begin{aligned}
& \mathrm{C}_{\mathrm{MД}} \approx \mathrm{C}_{\mathrm{T}}, \\
& \mathrm{C}_{\mathrm{TM}} \approx \mathrm{C}_{\mathrm{T}} .
\end{aligned}
$$

де $\mathrm{C}_{\mathrm{T}}$ - досягнута швидкість передачі.

Експлуатаційна пропускна спроможність $\left(\mathrm{C}_{\mathrm{e}}\right)$ характеризує реальну експлуатаційну швидкість передачі з урахуванням факторів, які знижують можливості каналів зв'язку по передачі інформації. Співвідношення між теоретичною, технічною та експлуатаційною пропускною спроможністю можливо описати наступними виразами:

$$
\mathrm{C}_{\mathrm{T}}=\mathrm{k}_{\mathrm{T}} \mathrm{C}, \mathrm{k}_{\mathrm{T}}<1 ; \mathrm{C}_{\mathrm{e}}=\mathrm{k}_{\mathrm{e}} \mathrm{C}_{\mathrm{T}}, \mathrm{k}_{\mathrm{e}}<1 ;
$$

або

$$
\mathrm{C}_{\mathrm{e}}=\mathrm{k}_{\mathrm{e}} \mathrm{k}_{\mathrm{T}} \mathrm{C} \text {. }
$$

де $\mathrm{C}_{\mathrm{e}}{ }^{-}$експлуатаційна пропускна спроможність;

$\mathrm{k}_{\mathrm{e}}-$ коефіцієнт, що враховує зниження теоретичної пропускної спроможності за рахунок використання технічних рішень. які не повністю реалізують потенціал каналу зв'язку;

$\mathrm{k}_{\mathrm{T}}$ - коефіцієнт, що враховує зниження

технічної пропускної спроможності за

рахунок експлуатаційних втрат.

Коефіцієнти у виразах (5) враховують реальні засоби телекомунікації та умови експлуатації каналів зв'язку. Таким чином для пропускної спроможності мережі доступу та транспортної мережі на напрямках зв'язку від (4) доцільно перейти до співвідношення

$$
\mathrm{C}_{\mathrm{MД}(\mathrm{TM})} \approx \mathrm{C}_{\mathrm{e}}=\mathrm{k}_{\mathrm{e}} \mathrm{k}_{\mathrm{T}} \mathrm{C} .
$$

При цьому виконувати вимірювання потенційно досяжної пропускної спроможності каналу зв'язку не є доцільним. Достатньо обмежитися умовами (6) та перейти до спрощеного запису

$$
\mathrm{C}_{\mathrm{MД}(\mathrm{TM})}=\mathrm{k}_{\mathrm{e}} \mathrm{C}_{\mathrm{T}} .
$$

Звідси

$$
\lambda \leq \mathrm{k}_{\mathrm{e}} \mathrm{C}_{\mathrm{T}},
$$

де

$\mathrm{C}_{\mathrm{T}}$ - трактується як швидкість передачі даних конкретним засобом зв'язку у канал зв'язку та визначається його технічними характеристиками.

Фактично пропускна спроможність транспортної та мережі доступу буде обмежуватись технічними характеристиками засобу зв'язку та умовами функціонування каналу зв'язку. Ключовою вимогою для забезпечення своєчасного обміну необхідним об'ємом інформації є дотримання нерівності (8). Таким чином завдання визначення вимог до пропускної спроможності (корисного навантаження) мережі доступу та транспортної мережі зводиться до відпрацювання методики визначення інтегральної швидкості передачі інформації від кінцевих користувачів $(\lambda) \quad 3$ урахуванням кількості абонентів, розгорнутих сервісів та інформації сенсорних мереж. Аналітичний опис $(\lambda)$ надасть можливість визначити вимоги до варіантів організації системи військового зв'язку (побудови транспортної мережі та мережі доступу). У свою чергу це надасть можливість сформувати вимоги до тактико-технічних характеристик існуючої та перспективної техніки зв'язку. При цьому знайдене формалізоване значення сумарного пікового навантаження всіх користувачів на напрямку зв'язку для кожної ланки управління надасть можливість сформувати вимоги до тактико-технічних характеристик техніки зв'язку у ланках солдат - відділення - взвод - рота батальйон - бригада - і так далі.

Важливим аспектом запропонованого підходу буде зменшення надлишковості у замовлені оренди цифрових потоків в операторів телекомунікаційних послуг. Такий підхід надасть можливість зменшити витрати коштів Збройних Сил України на оплату оренди цифрових потоків. Значне місце при організації зв'язку займає використання телекомунікаційної мережі загального користування. При цьому в операторів 
замовляються послуги MPLS (Multiprotocol Label Switching) другого рівня, що відповідає канальному рівню мережевої моделі OSI (open systems interconnection basic reference model). Технологія MPLS використовується для побудови віртуальних приватних мереж VPN (Virtual Private Network) 3 метою передачі трафіку: IP (Internet Protocol) пакетів, збірок ATM (Asynchronous Transfer Mode), фреймів SDH (Synchronous Digital Hierarchy), кадрів Internet. Перераховані види трафіку відповідають мережевому, третьому, рівню моделі OSI. Наступним іiі рівнем $\epsilon$ транспортний, четвертий рівень, який призначений для забезпечення надійної передачі даних від відправника до отримувача. Основні протоколи транспортного рівня це UDP (User Datagram Protocol) та TCP(Transmission Control Protocol). Протокол UDP обмежується контролем цілісності даних у межах однієї дейтаграми та не виключає втрати цілого пакету, його дублювання або порушення порядку отримання пакетів даних. Протокол ТСР забезпечує надійну безперервну передачу даних, що виключає втрату даних або порушення порядку їх отримання.

За досвідом проведення АТО та навчань 3 військовими частинами та підрозділами зв'язку пропускна спроможність орендованих цифрових каналів під час активізації роботи органів управління знижується.

Реальна пропускна спроможність системи військового зв'язку на основі “тунелів” VPN значно менша від заявлених у договорах оренди величин. Ситуація ще більш погіршується із збільшенням часу затримки пакетів під час проходження по мережі зв'язку, що негативно впливає на своєчасність та достовірність зв'язку. Традиційним методом боротьби у Збройних Силах України за якість зв'язку у цьому випадку $є$ збільшення пропускної спроможності, що орендується у операторів телекомунікації. Але такий метод довів свою неефективність на практиці. Він мало впливає на якість зв'язку та значно збільшує фінансові витрати на оренду.

Існуючі наукові та науково-методичні праці 3 питань оцінки пропускної спроможності системи зв'язку військового призначення та цивільних систем зв'язку до 2014 року мали ряд розбіжностей. Методологічні основи оцінки якості військового зв'язку були орієнтовані на аналогові військові засоби зв'язку та датуються 80-ми роками минулого століття, але зазначені підходи втратила свою актуальність 3 моменту переходу 3С України на цифрове телекомунікаційне обладнання.

Такий стан справ викликаний не розумінням організаторами зв'язку взаємодії рівнів моделі OSI. Для прояснення існуючої ситуації розглянемо мережу на основі Ethernet, як самої популярної технології на даний час. При цьому не будемо розглядати середовища передачі даних. Основними показниками якості мережі будуть наступні:1. Пропускна спроможність (bandwidth).
2. Пакетна пропускна спроможність (PPS,Packets Per Second), яка відображає скільки фреймів може бути передано за одиницю часу.

3. Показник втрат фреймів (frame loss), який показує скільки фреймів неможливо відновити або їх контрольні суми не збігаються від загальної кількості фреймів.

4. Затримка пакетів (delay, latency) - час через який пакет відправлений з точки А опиниться у точці В. При цьому різняться одностороння затримка (one-trip) та кругова (round-trip).

5. Мінімальний MTU (Maximum Transmission Unit) - максимальний об'єм даних, що може бути переданий протоколом за одну ітерацію. Цей показник критичний для важких програм (підтримка АСУ, високоякісне потокове відео та інше).

6. Берстність - нормована максимальна бітова швидкість. Вона дозволяє оцінювати розмір буферу обладнання мережі та прораховувати умови надійності.

Питання впливу на пропускну спроможність часу затримки та втрат пакетів для транспортного рівня в потоках трафіку ТСР та UDP були досліджені Борисом Рогієром (Boris Rogier) та описані ним в [6]. Причинами зменшення пропускної спроможності мережі вказуються неправильно розраховане навантаження мережі, неправильна конфігурація мережі, дефекти обладнання та інші. При цьому пропускна спроможність трактується як кількість даних, що надсилаються (отримуються) за одиницю часу. Втрати відображають кількість пакетів, втрачених із 100, відправлених хостом.

Встановлено, що теоретично затримка не впливає на пропускну спроможність для протоколу UDP. Більш складний випадок виникає при використанні протоколу ТСР, який регулює довжину дейтаграми, MTU (вікно завантаження протоколу ТСР), у залежності від часу отримання підтвердження правильності доставки пакетів.

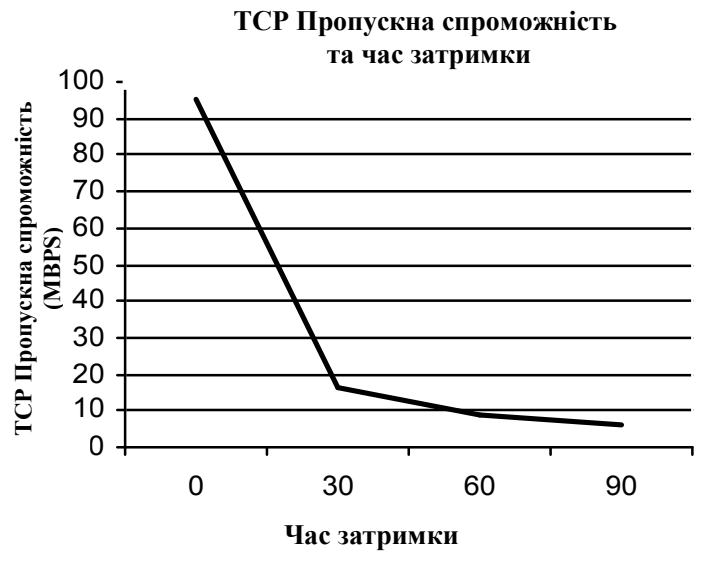

Рис. 1. Залежність пропускної спроможності протоколу ТСР від часу затримки.

На рисунку 1 наведена залежність пропускної спроможності протоколу ТСР від часу затримки (Latency) при вхідному навантаженні 100 Мбіт/с. 
Більш критичною є втрата пакетів у мережі. У такому випадку вікно завантаження ТСР зменшується вдвічі та виникає потреба у повторній передачі втрачених пакетів. На рис. 2 наведена залежність пропускної спроможності від часу затримки пакетів за умови втрат 2\% пакетів.

Вплив втрати пакетів та часу затримки на пропускну спроможність ТСР

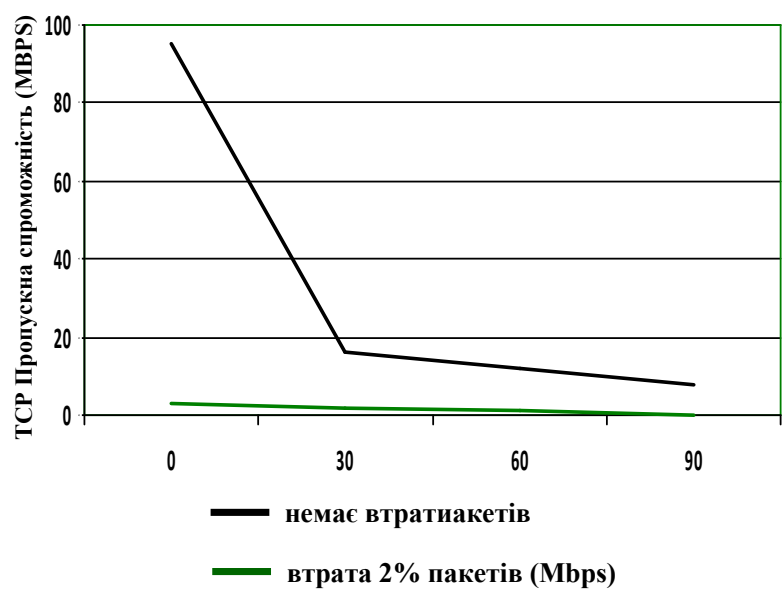

Рис. 2. Порівняльні графіки залежності пропускної спроможності протоколу ТСР від часу затримки за умови втрат 0 (верхній графік) та 2 \% пакетів (нижній графік).

Таблиия 1

\begin{tabular}{|c|c|c|c|c|}
\hline Васрата & $0 \mathrm{Mc}$ & $30 \mathrm{Mc}$ & $60 \mathrm{Mc}$ & $90 \mathrm{Mc}$ \\
\hline 0 & $\begin{array}{c}93,5 \\
\text { Мбіт/c }\end{array}$ & $\begin{array}{c}16,2 \\
\text { Мбіт/c }\end{array}$ & $\begin{array}{c}8,7 \\
\text { Мбіт/c }\end{array}$ & $\begin{array}{c}5,32 \\
\text { Мбіт/c }\end{array}$ \\
\hline $2 \%$ & $\begin{array}{c}3,72 \\
\text { Мбіт/с }\end{array}$ & $\begin{array}{c}1,63 \\
\text { Мбіт/c }\end{array}$ & $\begin{array}{c}1,33 \\
\text { Мбіт/c }\end{array}$ & $\begin{array}{c}0,85 \\
\text { Мбіт/с }\end{array}$ \\
\hline
\end{tabular}

Залежність пропускної спроможності протоколу ТСР від часу затримки та показника втрат пакетів.

Графік та данні таблиці свідчить, що 3 втратою 2\% відсотків, пропускна спроможність протоколу ТСР зменшується від 6 до 25 раз у порівнянні 3 роботою без втрат. В ЗС України апаратура криптографічного захисту під час обробки інформації використовує протокол UDP.

\section{Лimepamypa}

1. Матеріали доповідей науково-практичного семінару кафедри зв'язку і АСУ "Перспективи бойового застосування військ звязку ЗС України”. - Київ: НУОУ, 2016. - С.110. 2. Аналіз Генерального штабу ЗСУ щодо бойових дій на Дебальцевському плацдармі з 27 січня до 18 лютого 2015 року.http://www.mil.gov.ua/analitichnimateriali/ 3. Боговик А. В. Эффективность систем военной связи и методы ее оценки / А. В. Боговик, В. В. Игнатов - СПб.: ВАС, 2006. - 183 с. 4. Куприянов А. И.
Використання даного протоколу для забезпечення зв'язку із зазначеною якістю накладає ще більш жорсткі вимоги до характеристик каналів мережевого доступу та транспортної мережі. Втрата пакетів призводить до переривів звязку та особливо під час надання послуг в режимі реального часу (відео конференц зв'язок, телефонія). Наведене свідчить про необхідність ефективного управління транспортною мережею для забезпечення іiї необхідної пропускної спроможності відповідно до нерівності $\mathrm{C}_{\mathrm{Mд}} \leq \mathrm{C}_{\mathrm{TM}}$.

Висновки й перспективи подальших Проведений у статті аналіз факторів, які впливають на ефективність функціонування системи військового зв'язку та аналіз сучасного стану функціонування системи зв'язку Збройних Сил показав, що напрямком подальшого дослідження $\epsilon$ удосконалення науковометодичного апарату з питань оцінки ефективності функціонування системи військової зв'язку за пропускною спроможністю. А це в свою чергу потребує вирішення наступних часткових завдань:

1. Удосконалити метод розрахунку пропускної спроможності мережі доступу до транспортної мережі системи зв'язку за умови зростання інформаційного обміну, реалізації мультисервісних мереж надання послуг на пунктах управління та переході 3С України на сучасні цифрові методи передачі інформації.

2. Розробити метод ефективного управління наявними ресурсами транспортної мережі системи зв'язку ЗС України для гарантованого забезпечення необхідної пропускної спроможності системи зв'язку в складних умовах ведення бойових дій.

3. На основі розроблених методик обгрунтувати рекомендації щодо оперативнотехнічних характеристик засобів телекомунікацій у різних ланках управління.

Подальші дослідження будуть направлені на розробку методів (методик) розрахунку пропускної спроможності, які підвищать ефективність функціонування системи зв'язку, до рівня який забезпечить безперервне управління військами.

Радиоэлектронные системы в информационном конфликте. / А. И. Куприянов, А. В. Сахаров - М.: Вузовская книга, 2003. - 528 с. 5. Куприянов А. И. Теоретические основы радиоэлектронной борьбы / А. И. Куприянов, А. В. Сахаров. - М.: Вузовская книга, 2007. - 356 c. 6. Boris Rogier Network performance : Links between latency throughput and packet loss/ Categories: Network performance/ July 13th, 2016|URL $\mathrm{http}$ ://blog.performancevision.com/eng/earl/links-between-

latency-throughput-and-packet-loss (20)

\section{К ВОПРОСУ ПРОПУСКНОЙ СПОСОБНОСТИ В КАЧЕСТВЕ ОСНОВНОГО ПОКАЗАТЕЛЯ}




\title{
ЭФФЕКТИВНОСТИ ФУНКЦИОНИРОВАНИЯ СИСТЕМЫ ВОЕННОЙ СВЯЗИ
}

\author{
Андрей Александрович Зинченко (д-р. техн. наук, доцент) ${ }^{1}$ \\ Александр Николаевич Нестеров ${ }^{1}$ \\ Катерина Андреевна Зинченко ${ }^{2}$ \\ ${ }^{1}$ Национальный университет обороны Украины имени Ивана Черняховского, Киев, Украина \\ ${ }^{2}$ Военный институт телекоммуникаций и информатизации имени Героев Крут, Киев, Украина
}

В статье на основе проведенного анализа установлено несоответствие между существующим научно-методическим аппаратом оценки эффективности функиионирования системь военной связи, который ориентирован на аналоговые методы передачи данных, и совершенным переходом системы военной связи на цифровые средства связи. Обоснована необходимость: совершенствование метода расчета пропускной способности сети доступа к транспортной сети системь связи в условиях перехода на современные иифровые методы передачи информачии, рост информационного обмена, реализации мультисервисных сетей оказания услуг; разработки метода управления имеющимися ресурсами транспортной сети системы военной связи для гарантированного обеспечения необходимой пропускной способности системы связи в сложных условиях ведения боевых действий. В дальнейшем, усовершенствованные методы могут быть использованы для обоснования требований к системе военной связи в боевых действиях (операциях).

Ключевые слова: система связи, система управления, информационное направление, информачионная система, канал связи, пропускная способность, автоматизированная система управления.

\section{TO THE QUESTION OF LOCAL CAPACITY AS THE BASIC INDICATOR OF THE EFFICIENCY OF THE FUNCTIONING OF THE MILITARY COMMUNICATION SYSTEM}

Andrii O. Zinchenko (Doctor of Technical Sciences, Associate Professor) ${ }^{1}$

Oleksandr M. Nesterov ${ }^{1}$

Catherine A. Zinchenko ${ }^{2}$

\author{
${ }^{1}$ National Defence University of Ukraine named after Ivan Cherniakhovsky, Kyiv, Ukraine \\ ${ }^{2}$ Military Institute of Telecommunications and Informatization the name of the Heroes of Kruty, Kyiv, \\ Ukraine
}

In the article on the basis of the conducted analysis the discrepancy between the existing scientific and methodical apparatus for assessing the effectiveness of the functioning of the military communication system, which is oriented on analog data transmission methods, and the implementation of the transition of the military communication system to digital communication means has been established. The necessity of: improving the method of calculating the bandwidth of the access network to the transport network of the communication system in the conditions of transition to modern digital methods of information transmission, the growth of information exchange, implementation of multiservice networks of service provision; development of the method of management of available resources of the transport network of the military communication system for the guaranteed provision of the necessary throughput capacity of the communication system in the difficult conditions of the conduct of hostilities. Subsequently, improved methods can be used to substantiate the requirements for a military communication system in combat operations (operations).

Key words: communication system, control system, information direction, information system, communication channel, bandwidth, automated control system.

\section{References}

1.Materials of reports of the scientific and practical seminar of the department of communication and control systems "Perspectives of military use of the Armed Forces of the Armed Forces of Ukraine". - Kyiv: NUOU, 2016. - P.110. 2. Analysis of the General Staff of the Armed Forces on combat operations on the Debaltsevsky bridgehead from $\begin{array}{lllll}\text { January } 27 \text { to } & \text { February } 18,2015 .\end{array}$ http://www.mil.gov.ua/analitichni-materiali/ 3. Bogovik A.V. Efficiency of military communication systems and methods its estimates / A.V. Bogovik, V.V. Ignatov - SPb .: YOU, 2006. - 183 p. 4. Kupriyanov A.I. Radioelectronic
Systems in the Information Conflict. / AI Kupriyanov, AV Sakharov - Moscow: Vuzovskaya book, 2003. - 528 p. 5. Kupriyanov A.I., Theoretical Foundations of the RadioElectronic Struggle / AI Kupriyanov, AV Sakharov. Moscow: Vuzovskaya book, 2007. - 356 p. 6. Boris Rogier Network performance : Links between latency throughput and packet loss/ Categories: Network performance/ July 13th, 2016|URL http://blog.performancevision. com/ eng/earl/links-between-latency-throughput-and-packet-loss (20) 